\title{
Consideraciones lexicográficas a partir de las "papeletas» de Ricardo Palma: por una lexicografía más inclusiva y por una mayor competencia léxica
}

\author{
Miguel Ángel Vega Cernuda \\ Universidad de Alicante \\ carsacer@gmail.com \\ Alicante-España
}

\section{Resumen}

Partiendo del objetivo que llevó Ricardo Palma en su viaje a la Península en 1891, la ampliación del tesoro lexicográfico de la lengua española, notamos que su obra, reflejada en las Papeletas lexicográficas, no fue en vano, aunque, a pesar del enriquecimiento que se ha producido desde entonces, queda todavía mucho por hacer. El examen de cuatro textos hispanoamericanos nos permite identificar un número significativo de lemas que aún no aparecen en nuestras lexicografías.

Palabras clave. Lexicografía española, Ricardo Palma, diccionarios españoles, diatopismo, americanismos, lexicografía y traducción.

\section{Abstract}

Starting from the purpose that led Ricardo Palma to the Peninsula in 1891, the expansion of the lexicographical treasure of the Spanish language, we can see that his work, reflected in Papeletas lexicográficas, was not in vain, although, despite the enrichment that has taken place since then, there is still much to be done. The analysis of four Spanish-American texts allows us to identify a significant number of mottos that still do not appear in our lexicographies.

Keywords: Spanish lexicography, Ricardo Palma, Spanish Dictionaries, diatopism. Lexicopraphy and Translation. 


\section{Miguel Ángel Vega Cernuda (España)}

Profesor titular (U. Complutense). Catedrático (U. de Alicante, actualmente jubilado. Estudios de Filosofía y Teología (19601966). Estudios de Filología Moderna (Licenciado en Filología Moderna. 1969-1973) en U. Complutense. Becado en Tubinga (DAAD, 1973-75), Viena (ÖAD, 1980) y Berlín (DAAD, 1985). Doctor en Filología Alemana. Estancias de formación en Nimega, Perugia, Gante, Oxford, Lübeck (DAAD), Arles, Procida, Aarhus. Diversas distinciones internacionales. Profesor visitante de la U. de Münster (200-2012). Director del Instituto Universitario de Traductores Complutense (1987-2003). Autor de un centenar de artículos y una docena de libros. (Temas: literaturas en lengua alemán, historia y teoría de la traducción, literatura misionera). Traductor literario (treinta títulos de alemán, italiano, francés, danés: Casanova, Jacobsen, Goethe, Schnitzler. Haertling, etc.) 


\section{Motivación del trabajo}

En mi contribución a los actos conmemorativos del centenario de la muerte de Ricardo Palma pretendo remarcar que en el camino hacia lo que podíamos denominar la «lexicografía hispánica inclusiva» (si no iniciada, sí vivamente defendida por el epónimo de nuestra Universidad) queda todavía mucho camino por andar. Desde que en 1726 apareciera el primer volumen de lo que sería la primera lexicografía oficial del español (el Diccionario de autoridades), se puso en evidencia una centropatía lingüística, entonces, quizás justificada, pero que en todo caso desatendía la riqueza léxica imperante en el uso de nuestra lengua. No sería inexacto hablar de «centrocentrismo», considerando que el uso que básicamente se atendía a la hora de confeccionar el diccionario era el del «centro», no tanto el geográfico, que también, cuanto el socio-político del idioma español. Tampoco usos regionales de la Península (valores diatópicos del léxico) tenían entrada en aquella inicial lexicografía, no digamos nada de los lemas propios de los territorios de Ultramar, cuya habla había derivado, dice M. Alvar López, del andaluz occidental. Desde entonces son muchas las actualizaciones que nuestras lexicografías han experimentado desde que las hablas hispanas, regionales o nacionales, empezaron a seguir los cauces del uso propio, en parte perpetuando usos de antaño que la Península perdía. Sobre todo a partir de los años de la Independencia, hace doscientos años. En la página electrónica de la $\operatorname{RAE}^{1}$ se recogen los hitos de esa ampliación lexicográfica que pasó de los 49.000 artículos de la edición de 1780 (Diccionario de la lengua castellana reducido a un tomo para su más fácil uso) a los 59.000 de la cuarta edición 1803 para acabar en los 93.000 de la vigésimo cuarta edición de 2014, logro importante a pesar de que en ediciones anteriores se hubieran eliminado las entradas correspondientes a los adverbios en «mente» o a los

1 https://www.rae.es/diccionario-de-la-lengua-espanola/presentacion 
participios pasados. Sin embargo, en la modesta opinión del que esto escribe, esta lexicografía inclusivista, es decir, la que pretende incluir sobre todo las variantes diatópicas, está todavía inconclusa. Y no solo por culpa de la «docta corporación» como más abajo señalaremos. En todo caso, si contrastamos con los tesauros léxicos de otros idiomas resultan unos cuadros que ponen de manifiesto que el empeño de Palma por abrir nuestra lexicografía tenía sobrada razón.

No se presentan estas consideraciones con pretendida y pretenciosa voz de especialista, sino como producto de lecturas de la literatura hispana y como resultado de reflexiones en la práctica e investigación de la traducción, que con frecuencia obligan a plantearse el uso adecuado de un lema, de una colocación, de una unidad fraseológica o de un modismo; o que constatan la imposibilidad de equivalencia léxica entre las lenguas en contraste que la versión presenta.

\section{Los talantes lexicográficos: de Ricardo Palma a la tendencia reduccionista de algunas corporaciones lexicográficas}

Como hilo introductorio de mi exposición voy a empezar recordando un episodio de la vida de Don Ricardo Palma, por lo demás de sobra conocido. Cuando Ricardo Palma emprende por segunda vez viaje a Europa, en 1891 (en esta ocasión propuesto por el gobierno peruano e invitado por la Real Academia de la Lengua Española, para participar en los fastos que conmemoraban el centenario del Descubrimiento de América), lleva consigo una serie de propuestas léxicas de americanismos ante la docta institución que —en aras del común entendimiento de los hispano-hablantes - esta debería integrar en el diccionario. El talante con el que venía don Ricardo quedaba explícito en muchas de sus afirmaciones. 
Solo mencionaré una: «El espíritu, el alma de un idioma, está en su sintaxis más que en su vocabulario. Enriquézcase éste y acátese aquella, tal es nuestra doctrina» (Palma, 2003, p. 9). Era un talante que estaba muy lejos de aquel con el que algunos doctos porteños intentaban realizar la separación definitiva del origen y la tradición españoles a través del idioma, y del que es buen ejemplo aquel savonarola lingüístico que se llamó Juan María Gutiérrez, quien ya en 1837, en una reunión de iniciados, como en sociedad secreta, afirmaba su pretensión de romper lazos definitivamente con el pasado español. También los lingüísticos:

Quedamos aún ligados por el vínculo fuerte y estrecho del idioma; pero este debe aflojarse de día en día, a medida que vayamos entrando en el movimiento intelectual de los pueblos adelantados de la Europa. Para esto es necesario que nos familiaricemos con los idiomas extranjeros, y hagamos constante estudio de aclimatar al nuestro cuanto en aquellos se produzca de bueno, interesante y bello (2004, p. 8$)^{2}$.

El talante de Palma iba más en consonancia con el del maestro Andrés Bello quien, a pesar de confesar que no escribía para castellanos, pretendía una escritura uniformada de España y de las naciones americanas que así presentaría un grado de perfección desconocida en el mundo. Que este talante lexicográfico de Palma se anticipaba no solo a su tiempo sino también a más de una institución queda en evidencia no solo

2 Se ha escrito mucho acerca del independentismo lingüístico de la intelectualidad porteña de la Generación de 1837. Rodolfo Alonso (2005). «Juan María Gutiérrez. Contra la Academias». En: Archipiélago. Vol. 13, № 47. con ocasión del III Congreso de la Lengua Española en Rosario, hace una glosa, un tanto añorante, al que remitimos, al igual que al artículo — del que tomamos la cita—, de José Luis Moure, «Norma nacional y prescripción. Ventajas y perjuicios de lo tácito». Recuperado de cvc.cervantes.es/obref/congresos/rosario/ponencias/ aspectos/moure_jl.htm. 
en la confrontación que tuvo con alguno de los miembros de la RAE, sino también si lo comparamos con los criterios de confección lexicográfica de algunas instituciones actuales. Palma no coincidiría con el criterio con el que se ha confeccionado el Grand Robert francés que mencionamos abajo y sí, por el contrario, con el seguido por los responsables de la lexicografía inglesa oficial de hoy en día, la que confecciona el Oxford English Dictionary. En sus propuestas iniciales este diccionario advierte:

The aim of this dictionary is to present in alphabetical series the words that have formed the English vocabulary from the time of the earliest records down to the present day with all the relevant facts concerning their form, sense-history, pronunciation, and etymology (1991, p. VII).

El resultado de este criterio lexicográfico es que el OED contains about 290.500 entries, or about 38.000 more than in the first edition. Es un talante lexicográfico de apertura que, por ejemplo, queda en franca contradicción con la purista lexicografía francesa y, en parte, la española. Le Grand Robert de la langue française (2001) advierte el carácter selectivo de su trabajo:

Outre la rigueur, l'exactitude d' une langue, la qualité de ce genre d' ouvrage requiert des choix. Choix des «entrées», dans la forêt des neologismes, des emprunts, des sigles que chaque annéé apporte, choix de normes, plus ou moins libérales, toujours sélectives sous peines de chaos, choix des informations et de déférences. (XI).

El resultado de ese choix des entrées es un diccionario de solo 80.000 palabras du francais classique, moderne et très contemporaine. Este mismo talante reduccionista es el que se percibe en el Diccionario esencial español de la RAE (2006), que si bien confiesa responder el «léxico común y culto actual», creemos que se muestra muy restrictivo al prescindir por completo 
del vocabulario cronológicamente desfasado [...] no solo suprime las entradas del DRAE que corresponden al léxico medieval (señaladas con la marca «ant»), al posterior a 1500 y anterior a 1900 («desus») o al que desaparece durante las primeras décadas del siglo XX (s.f., p. XVII)

Personalmente he realizado algunas someras comprobaciones que me hacen dudar de que con semejante diccionario, que, al denominarse «esencial», debería ser suficiente para poder leer comprensivamente textos literarios o sociológicos del siglo XIX, se pudieran desentrañar las delicias léxicas de las Tradiciones de Palma. Valgan algunos ejemplos: en «Un proceso contra Dios» (1893, p. 283) nuestro limeño escribía con el gracejo característico «los golillas perdían su latín» (ibíd., p. 289). Difícilmente el Diccionario le servirá al traductor para desentrañar exactamente el sentido de la frase al no estar recogida la acepción de «golilla», no digamos ya la unidad fraseológica «perder el latín». En otra «tradición», «Cortar el revesino» (ibíd., p. 270), don Ricardo le hace al virrey peruano «sorber una narigada» (ibíd., p. 271). Solo el contexto, tratándose de rapé, permite conocer el significado del vocablo, «narigada», que tampoco encuentra acogida en el diccionario. «Si sería chinchirinada $[\ldots] »$, escribe Palma en otra ocasión refiriéndose a la vanidad de una virreina («Beba, padre, que le da la vida», ibíd., p. 252), expresión que no hemos encontrado recogida ni en el CORPES XXI, por lo que sin duda entrañará una dificultad insalvable al potencial traductor ${ }^{3}$.

Cualquier usuario profesional de los elencos lexicográficos (el crítico e historiador de la literatura, el investigador de la historia de la traducción o el traductor mismo) comprobará la enorme

3 En otra ocasión hemos señalado que una de las dificultades para la internacionalización de la obra de Palma puede estribar en las dificultades que comporta su apabullante riqueza de vocabulario. 
cantidad de obras lexicográficas que tiene a su disposición (Robert, Larousse, Duden, Grimm, María Moliner, DRAE, Manuel Seco, Duden, Zanichelli, Garzanti, UTET, OED...), que, sin embargo, en ocasiones no le alcanza para resolver sus dudas o perplejidades léxicas. Uno de los ítems metodológicos de cualquier diccionario con pretensiones de validez relativamente- definitiva es el de la exhaustividad. No en último término, la variedad de criterios aplicados en la selección de las voces usadas, selección que se enfrenta al triple desafío de lo diacrónico, lo diatópico y lo diastrático, es lo que determina la coherencia y utilidad de un diccionario. Mientras que el Grand Robert francés cree que en la exhaustividad se esconde el caos y limita el corpus léxico a unas 80.000 voces, el Oxford English Dictionary opta por un criterio acumulativo que integra en su corpus léxico los registros literario, coloquial, dialectal, técnico, de jerga, etc., lo que hace que el número de entradas del diccionario principal, a las que se suman las recogidas en los suplementos, ascienda al medio millón de registros. El mismo criterio parece seguir el autor del gran diccionario portugués, que se lamenta de la «evaporización» de las palabras.

Por lo que respecta a la lexicografía española, parece haber nadado entre dos aguas: entre la metodología selectiva y la acumulativa. De hecho, hasta recientemente, el diccionario realizado por la figura estelar de María Moliner (ivergüenza para la docta institución por no haberla acogido en su seno!), resultaba de mayor utilidad que el de la RAE gracias a su mayor exhaustividad. Percepción esta que se intensificaba si se contrastaba con el Diccionario esencial de la lengua española (2006). A Palma, en su «viaje español», que, a juzgar por su correspondencia y el desarrollo posterior de los acontecimientos, no le dejó del todo insatisfecho, solo se le aceptaron algunas de sus propuestas léxicas, si bien con su presencia y su insistencia machacona abrió una puerta a la inclusión y la comprensión de 
la variación lingüística que, poco a poco, fue enriqueciendo el DRAE. Gracias a su empeño hoy el DRAE (Diccionario de la Real Academia Española) se ha convertido en el DLE (Diccionario de la Lengua Española). Y un único ejemplo de la razón que le asistía a don Ricardo bastaría para convencerse de la necesidad de su empresa: el que abogara por la incorporación, entre otras, de una voz hoy en día tan usual como es el de «oportunismo». ¿Qué haríamos hoy en día sin el uso de un término de tanta aplicación a la hora de enjuiciar comportamientos humanos, sobre todo en el ámbito social y político? Huelga decir que la empresa, insistimos, si no iniciada por Palma, sí promovida con gran empeño desde su cargo, con el trascurso del tiempo, dio lugar a unas realidades que se han demostrado inapreciables para el mencionado común entendimiento del grupo hispanohablante, cuales son el nuevo Diccionario de la lengua española (2014), el Diccionario panhispánico de dudas (2005), o el Diccionario de americanismos (2010), de los cuales se puede considerar a Palma como uno de sus principales mentores. Gracias a él, aunque, por supuesto, no solo, la comunidad de hablantes del español ha desarrollado una conciencia de riqueza léxica que anteriormente se impedía con los criterios restrictivos del purismo ${ }^{4}$.

\section{¿Existe un déficit lexicográfico español? O las dificultades léxicas del traductor}

A pesar del esfuerzo realizado por Ricardo Palma (y otros) en favor del enriquecimiento léxico y del ejemplo por él establecido, justo es confesar que nuestro tesoro lexicográfico no es de los más abundantes. Algunos cómputos de voces, más o menos

4 Nos parece omisión importante que el DA, en su «Presentación» no haga mención de la labor de Ricardo Palma, aunque no fuera él ni el único ni el primero que mostró esa conciencia de integración e inclusión lexicográfica. Solo habría que mencionar el diccionario de americanismos del cubano Picardo, realizado en una época todavía colonial. 
oficiales ${ }^{5}$, asignan al español un número relativamente escaso de lemas: 100.000 palabras. De esas 100.000 palabras españolas en el diccionario de 2014, 28.000 voces tendrían su origen en el español americano. La cifra, aunque sea aproximada, queda muy distante de las 500.000 palabras que el diccionario Hoepli asigna al italiano, o de las 190.000 que recoge y analiza el Gran Diccionario UTET, también italiano, sobre más de 14.000 obras de 7.000 autores. Y en alemán, el diccionario de los hermanos Grimm, iniciado en 1838, recoge en la actualidad unos 300.000 vocablos, cifra que el Duden eleva a 500.000 voces.

Es fácilmente conjeturable que, dado ese hiato cuantitativo de lemas o voces que existe entre el español y otras lenguas, el traductor «del» $\mathrm{O}$ «al» español tendrá más de una dificultad a la hora de enfrentar la equivalencia en el propio idioma de una voz extranjera de medio o escaso uso. Sin que esto aluda a una minusvalía expresiva de nuestro idioma, sí que pone en aprietos al usuario, bien sea un lector reflexivo o un traductor literario, que tendrá que salvar esa asimetría léxica con una reflexiva selección de la acepción de la voz en cuestión. Así, el lema español «muelle» puede tener tres equivalencias fundamentales, totalmente distintas, en alemán: Kai, si se trata de un muelle portuario; Rampe, si se trata de muelle de carga; o Feder, si se trata de un resorte. Y una cuarta en su forma adjetival: weich. Y aunque se podrían aducir ejemplos a la inversa (por ejemplo, el alemán Bild puede tener como equivalente en español «cuadro», de museo; o «foto», de revista), sí que resulta evidente que el uso del español ha tendido a la acumulación de significados en cada uno de los lemas. En efecto, el tesoro léxico del español se basa en la polisemia, es decir, en la acumulación de acepciones sobre un mismo lema, mientras que otros idiomas han desarrollado más lo que podíamos denominar «especificidad lémica» (es decir, la

5 Ver por ejemplo https://www.quieroaprenderidiomas.com/recursos-informacion/ lenguas-con-mayor-numero-de-palabras-o-vocabulario/ 
reserva de un lema concreto para un concepto determinado), generando nuevas palabras a través de los procedimientos de composición y derivación. Por eso, cuando en la actividad traductora se enfrenta el español con idiomas que han hecho un uso exagerado (se podría decir abuso) del primero de esos procedimientos «lexicogénicos», el versor español se encuentra en desventaja. Basta con considerar que los prefijos activos en la creación léxica alemana son casi una setentena, mientras que los del español apenas llegan a la cincuentena, para poder calibrar la desproporción o asimetría léxica resultante, por ejemplo, de la activación del módulo lexicogénico «prefijo + verbo simple», lo que, a la hora de establecer una correspondencia o equivalencia, el traductor tendrá que resolver a base de locuciones verbales o sintagmas ad hoc. El lema alemán Uhrfeder exigirá en español una duplicidad lémica expresada en un sintagma, «muelle de reloj», que, por supuesto no figurará como lexicalizado en español. Las consecuencias para el traductor derivadas de este dato son múltiples y solo mencionaré la problemática que en general sobreviene en la traducción del verso alemán al español, cuando se quiere guardar la isometría rítmica. No es tarea fácil la reproducción de octosílabos o endecasílabos alemanes en español, sobre todo teniendo en cuenta la abundancia de lemas simples monosilábicos en la lengua alemana.

Permítaseme aducir un ejemplo de este anisomorfismo léxico, es decir, de ese distinto procedimiento de formación de palabras activado en cada una de las dos lenguas que me veo obligado a constatar y comparar en mi tarea de traductor: el verbo alemán arbeiten, trabajar, puede presentar en el uso, entre otras, las siguientes composiciones (según el diccionario Pons, 2017) que, teniendo como núcleo significativo el esfuerzo para hacer una cosa, a través de prefijos, recibe matices que hacen difícil la fijación de su correspondencia española y que siempre habrá que determinar en función de su contexto. 
abarbeiten (terminar de trabajar, pagar trabajando, agotarse), ausarbeiten (elaborar ampliamente, redactar, retocar), bearbeiten (elaborar, ocuparse, tramitar, arreglar, adaptar) durcharbeiten (trabajar a fondo, estudiar a fondo) einarbeiten (introducir en el tema, meter), mitarbeiten (colaborar en un asunto, cooperar) nacharbeiten (repasar el tema, mejorar, perfeccionar, copiar) überarbeiten (cansarse trabajando) verarbeiten (emplear, utilizar, manufacturar, transformar)

Para mejor comprensión de lo que decimos, explicitamos en dos cuadros lo que podíamos denominar la diversa metodología de creación léxica de los dos idiomas: La posibilidad de creación/ composición léxica a través de la combinación «prefijo/ preposición + verbo» es, como se puede comprobar, mucho mayor en alemán, lo que indiscutiblemente produce una mayor acumulación de lemas en su diccionario:

Contraste de posibilidades de composición léxica a través de la combinación pref./prep. + verbo en alemán y en español ${ }^{6}$ :

1) Formación de palabras con prefijo preposicional con cuatro verbos alemanes:

\begin{tabular}{|c|c|c|c|c|c|}
\hline $\begin{array}{c}\text { Prefijo/ } \\
\text { prepos. }\end{array}$ & $\begin{array}{c}\text { Verbos } \\
\text { arbeiten }\end{array}$ & Setzen & Legen & Machen & Fühlen \\
\hline $\mathrm{ab}$ & sí & sí & sí & sí & sí \\
\hline $\mathrm{an}$ & sí & sí & sí & sí & no \\
\hline $\mathrm{aus}$ & sí & sí & sí & sí & no \\
\hline $\mathrm{be}$ & sí & sí & sí & no & no \\
\hline bei & no & sí & sí & sí & no \\
\hline durch & si & sí & sí & sí & sí \\
\hline ein & si & sí & sí & sí & sí \\
\hline
\end{tabular}

6 No incluimos los prefijos incorporados de las lenguas clásicas (anti, hipo, hiper, etc.) pues estos se dan por igual en alemán. 


\begin{tabular}{|c|c|c|c|c|c|}
\hline $\begin{array}{c}\text { Prefijo/ } \\
\text { prepos. }\end{array}$ & $\begin{array}{c}\text { Verbos } \\
\text { arbeiten }\end{array}$ & Setzen & Legen & Machen & Fühlen \\
\hline ent & no & sí & sí & no & no \\
\hline für & sí & sí & sí & sí & no \\
\hline gegen & sí & sí & sí & sí & no \\
\hline in & no & no & no & no & no \\
\hline mit & sí & sí & sí & sí & sí \\
\hline nach & sí & sí & sí & sí & sí \\
\hline ohne & no & no & no & no & no \\
\hline seit & no & no & no & no & no \\
\hline über & sí & sí & sí & no & no \\
\hline um & sí & sí & sí & sí & no \\
\hline unter & no & sí & sí & no & no \\
\hline von & no & no & no & no & no \\
\hline vor & sí & sí & sí & sí & sí \\
\hline zwischen & no & sí & sí & no & no \\
\hline ver & sí & sí & sí & no & no \\
\hline
\end{tabular}

Los verbos señalados con «sí» admiten la composición con el correspondiente prefijo, de tal manera que el resultado de combinar los prefijos preposicionales, 21 , con 4 lemas simples verbales producen 76 palabras compuestas: abarbeiten, absetzen, ablegen, abmachen, abfühlen; ausarbeiten, auslegen, ausmachen, etc. ${ }^{7}$.

1) La aplicación de este procedimiento de creación/composición léxica (pref./prep. + verbo) al español a los correspondientes verbos da el siguiente resultado:

\begin{tabular}{|c|c|c|c|c|c|}
\hline $\begin{array}{c}\text { Prefijo/ } \\
\text { preposic }\end{array}$ & $\begin{array}{c}\text { Verbo: } \\
\text { trabajar }\end{array}$ & Poner & Sentar & Hacer & Sentir \\
\hline a & no & no & sí & no & si \\
\hline ante & no & sí & no & no & no \\
\hline bajo & no & no & no & no & no \\
\hline cabe & no & no & no & no & no \\
\hline con & no & sí & no & no & sí \\
\hline contra & no & sí & no & no & no \\
\hline de/di & no & no & no & sí & sí \\
\hline en/in & no & sí & no & no & no \\
\hline por & no & no & no & no & no \\
\hline pos & no & sí & no & no & no \\
\hline pre & no & no & sí & no & sí \\
\hline
\end{tabular}

7 Cada uno de estos verbos tiene su correspondiente entrada en el Diccionario Grimm. 


\begin{tabular}{|c|c|c|c|c|c|}
\hline $\begin{array}{c}\text { Prefijo/ } \\
\text { preposic }\end{array}$ & $\begin{array}{c}\text { Verbo: } \\
\text { trabajar }\end{array}$ & Poner & Sentar & Hacer & Sentir \\
\hline pro & no & sí & no & no & no \\
\hline sin & no & no & no & no & no \\
\hline so & no & sí & no & no & no \\
\hline sobre & no & sí & no & no & no \\
\hline trans & no & sí & no & no & no \\
\hline
\end{tabular}

Las 16 preposiciones combinadas con los correspondientes 4 verbos escogidos producen en español solo 17 nuevas palabras: asentar, anteponer, componer, consentir, etc. Cabe señalar que 2 preposiciones españolas son totalmente inválidas a la hora de la composición léxica: «bajo»y «cabe».

Así pues, frente a las enormes posibilidades de combinación que un lema alemán tiene con los prefijos preposicionales de los que dispone a la hora de ampliar o variar su significado, su semántica, a través de la composición léxica, el español debe responder con acumulación de significados sobre una misma palabra. A la inversa, una palabra simple española tendrá en alemán, a través de la composición, un número considerable de posibles correspondencias que según las acepciones o según la situación comunicativa serán de aplicación o no. Así, por ejemplo, el verbo español «introducir», verbo compuesto del prefijo «intro»y del lexema «duc» tienen las siguientes correspondencias compuestas en alemán:

$\begin{array}{ll}\text { introducir un libro, un movimiento } & \text { einleiten } \\ \text { introducir en un tema } & \text { einführen } \\ \text { introducirse en un tema } & \text { einarbeiten } \\ \text { introducir a fuerza de golpes } & \text { einschlagen } \\ \text { introducir de contrabando } & \text { einschmugeln } \\ \text { introducir con la fuerza un objeto en otro } & \text { einstecken } \\ \text { introducir a una persona, presentar } & \text { vorstellen }\end{array}$

En definitiva, entre el alemán y el español existe no solo una asimetría léxica sino también un anisomorfismo con referencia 
a lo que en lexicología se denomina «formación de palabras» (Wortbildung): mientras el español concentra sobre una palabra numerosos significados o acepciones (polisemia), el alemán prefiere crear nuevas unidades léxicas para expresar los posibles matices significativos que un concepto pudiera tener: concentración semántica en cada término frente a dispersión semántica de un lema o término.

De ello deriva el hecho lexicográfico de que el alemán tenga una mayor riqueza léxica... frente a una menor carga polisémica. Y quizás este statement se pueda aplicar a la comparación del español con otros idiomas.

Pero no es solo el mencionado anisomorfismo lexicográfico el responsable de la desproporción del quantum léxico constatable entre el alemán y el español. Cabría incluso sugerir una cierta renuencia (pereza) a la lexicogénesis o creación y acuñación de palabras en el usuario español. Gran parte de los americanismos recogidos en el diccionario son meras acepciones que enriquecen el significado, la polisemia de los términos, pero que no enriquecen el léxico con nuevas voces, sino el significado de cada uno de ellos, nutriendo el tema de acepciones. Así por ejemplo, en el vocablo «espada», existente por supuesto en el «español general» con una serie de significados, en el DA se le añade un cuarto, el de una planta herbácea de Méjico, para el que se da también la denominación, quizás de origen náhuat, ñisñil: ¿No habría sido mejor naturalizar como aztequismo en el español general este término a costa de reducir la polisemia de la voz «espada»?

En todo caso, cabe la pregunta: ¿cómo es posible esa enorme diferencia de vocablos disponibles en cada lengua (100.000 en español; 300.000 en alemán), sobre todo teniendo en cuenta que el español cubre una enorme amplitud espacial caracterizada por una gran diversidad biológica y geográfica, 
que abarca los dos hemisferios y tanto zonas templadas como selvas húmedas y desiertos tropicales? Lógicamente nuestro idioma debería ser una de las lenguas léxicamente más ricas, pues cabría pensar que, frente al español, otras lenguas de menor «extensión y comprensión geográficas», las nórdicas, por ejemplo, fueran más pobres a la hora de expresar el mundo de los manglares tropicales o de las pampas argentina, dado que estos representarían un conjunto de «reales» que les son ajenos. Si a ello se añaden las modulaciones léxico-semánticas que necesariamente aporta cada uno de los grupos humanos del diversificado conjunto hispanohablante (determinado por la pertenencia nacional, regional, comarcal, local, gremial o étnica) que llega a la lengua común con un mundo variadísimo de «realia» que, incluso siendo comunes, reciben en cada latitud y longitud distinta designación y connotación, sería perfectamente comprensible que el español tuviera una riqueza léxica de la que está lejos la relativa (si la comparamos con otros idiomas evolucionados) escasez lémica de nuestros diccionarios.

Y aquí conectamos con la tercera causa de la mencionada escasez: admitido que el español exprese lo nuevamente conocido por lo previamente conocido, en virtud de la percepción de las semejanzas implícitas entre los objetos (en este sentido cabría hablar de una «mentalidad metafórica» propia de nuestros hablantes) que hace que en el «muelle de carga», por ejemplo, se perciba un cierto efecto semejante al que tiene lugar en el «muelle como resorte», que mueve o eleva, cierto es, sin embargo, que nuestra lexicografía ha ido con el paso perdido. De esta manera de modular la percepción deriva su abundante polisemia y la riqueza de acepciones de un término. Pero, en definitiva, ¿por qué tradicionalmente el diccionario español, apelando, consciente o inconscientemente, a un mojigato purismo, no ha recogido e integrado en su sistema léxico los innumerables reales, las variantes y acepciones de cada lema que constituían el objeto de la expresión de sus hablantes? 
Verdad es que, en los últimos tiempos, la actitud, el talante ha cambiado. Hace unos años, el profesor complutense Emilio Lorenzo, posterior académico de la RAE, describía los nuevos aires mestizos del español: El español de hoy, lengua en ebullición (1971), donde, entre otras cosas, explicitaba la dialéctica entre lo antañón y lo novedoso. Hoy en día los préstamos o calcos del inglés invaden nuestras conversaciones, lo que no está mal, mientras designaciones en otro tiempo de moda en nuestro idioma van pasando al reservorio de arcaísmos (más bien habría que llamarlos «arqueologismos» lingüísticos, pues los reales correspondientes ya no existen) y se evaporan, lo que mal está. Hay muchos lemas, vocablos o unidades léxicas que andan «todavía» o «ya» en el uso escrito o hablado de las regiones del español que todavía no figuran en nuestros diccionarios, ni siquiera en el de americanismos ${ }^{8}$. Hay indigenismos (quechuismos, aymarismos, aztequismos) que, de relativamente frecuente uso en textos literarios, han tardado o tardan en penetrar en el DRAE/DLE. Pongo por caso el término «ayllu» que, desde que su uso se sancionó a través de la utilización realizada por Arguedas en Yawar fiesta (1977), ha pasado a ser una designación administrativa específica de las poblaciones andinas que debe figurar por derecho propio en un diccionario panhispánico. Sin embargo, no figuraba en el DRAE si no en la forma castellanizada «aillu». Y dígase lo mismo de «misti», de «killincho», «romazal» o «alaymosca», vocablos algunos de ellos ni siquiera recogidos en el Diccionario de americanismos. ¿Cómo podremos leer e interpretar la mencionada obra o Los ríos profundos (2001 [1958]) de Arguedas?

8 Hemos identificado más de un lema que, a pesar de la exhaustividad del CORPES XXI, todavía no figura en este corpus del español hodierno. 
Y es aquí donde se puede aplicar la justa pretensión de don Ricardo de enriquecer nuestro idioma común. Y no porque, en un intento paleto y provinciano, se intente revalidar y reivindicar lo propio, lo peculiar, sino por vindicar el sino propio de todo tesoro lexicográfico: el de la optimización de la expresión semántica. Si alguna función tiene un diccionario monolingüe que pretenda serlo en justicia, esta es

1) la de ayudar en la lectura comprensiva de los textos, literarios o no;

2) la de facilitar el contraste lingüístico que supone la traducción.

Y mientras «misti» o «romazal», por ejemplo, no figuren en el diccionario español, difícilmente figurarán en un diccionario bilingüe (español-alemán, por ejemplo) que servirá de base a la hora de realizar la versión de un texto en lengua propia a una lengua extranjera. El potencial versor de una obra de literatura hispana, pongamos por caso, la del costarricense Carlos Luis Fallas (2012 [1952]) Marcos Ramírez, ¿cómo podrá traducir «piapia», especie de urraca americana, mientras el término no figure en el diccionario? Bien es verdad que no se traducen las palabras, sino los textos, pero estos se construyen con aquellas. Difícil lo debió de tener la primera traductora de la obra de Arguedas al alemán (Juliane Bambula-Díaz, Berlín, 1980) si no estaba empapada de la cultura andina.

Y cierto es que también aquí impera el principio de la oferta y la demanda. El desconocimiento individual del propio idioma contribuye a ese desfase entre el sistema, la norma y el habla en un nivel léxico. El habla ha empobrecido su expresión y comodines léxicos como «tío», «macho» o «leche», por no mencionar otras expresiones, «mal-»y «peorsonantes» invaden la comunicación ordinaria en el español peninsular. La «leche» de la expresión «le dio de leches» (=le dio una tunda) no tiene 
nada que ver con la «leche» de la expresión «eres la leche» (=eres sorprendente, irregular, indisciplinado). Por otra parte, la comunicación intergrupal, la que realizamos a través de la lectura, funciona por compartimentos nacionales estancos. En nuestros países, la «lectura» didáctica, la que forma a los jóvenes, debería ser más comunitaria, y resulta penoso que un joven español conozca (como lector) a Faulkner, lo que no está mal, pero desconozca a Palma o, a la inversa, que un joven peruano conozca al autor americano y desconozca a Valle Inclán

\section{Lo que delatan algunos textos marcados: lo hecho y lo por hacer}

En la labor lexicográfica del español queda todavía mucho por hacer. Si siguiéramos la huella de don Ricardo, coleccionista en sus Papeletas lexicográficas (1903) de unidades léxicas por incorporar, deberíamos ir llenando las lagunas lexicográficas que son muchas y, en ocasiones, escandalosas. Como lector de obras literarias y crítico de traducciones he podido comprobar numerosos déficits lexicográficos de palabras que están funcionando en nuestro sistema de comunicación hablada y/o literaria. A riesgo de resultar aburrido o porfiado y para demostrar lo arriba afirmado, proponemos a continuación un análisis lexicográfico en cuatro textos americanos que muestran en qué medida la literatura de expresión en español constituye un fundus léxico todavía por explotar lexicográficamente con el objeto de dar mayor capacidad expresiva al hispanohablante. Hay mucha de esta literatura que todavía debe ser vaciada con un sentido amplio e inclusivo en el diccionario. Sobre todo teniendo en cuenta que al respecto más vale pecar por exceso que por defecto. El purismo lingüístico, en la época de la rebelión de las masas, del imperio del grupo, del «demos», ya no tiene sentido. 
Los cuatro textos literarios que utilizamos para este análisis los hemos escogido entre los muchos que nos han venido al encuentro en el uso lector o de consulta en los últimos tiempos. No hemos buscado ex professo textos donde se sospeche una abundancia de variantes léxicas, con el objetivo de

1) comprobar en qué medida nuestros diccionarios nos capacitan para descifrar todo el léxico presente en los mismos y, consiguientemente, hacer una lectura comprensiva de ellos;

2) mostrar la riqueza de variantes «diacronotópicas» que un texto semejante puede aportar a la recuperación lexicográfica de la lengua española; y

3) mostrar el enorme desfase o decalage, de hiato temporal que ha existido entre el uso lingüístico y el registro lexicográfico así como la progresiva recuperación de ese desfase. Cosa que por lo demás no debe extrañar, si se tiene en cuenta la actitud que hace más de un siglo mostraron muchos de los componentes de la docta institución ante las fundadas pretensiones de don Ricardo, que ya advertía del carácter parsimonioso del diccionario.

El primer texto que analizamos son Las maravillas de la naturaleza, de Juan de Santa Gertrudis (1970), doctrinero franciscano que en el siglo XVIII recorre lo que iba a ser el virreinato de Nueva Granada, estableciendo poblaciones de indígenas autónomas y describiendo aspectos de la naturaleza tropical y las costumbres de sus moradores en un valioso libro titulado con un sentido que responde a la espiritualidad de la orden. En el tomo cuarto, describiendo su paso desde Pasto a Lima, el relato revela la manera de hablar de un fraile «conversor» del siglo XVIII, marcado tanto por la diacronía como por la variante diatópica (peruano-colombiana) dentro del habla hispanoamericana. Tomamos al azar un capítulo, el primero del tomo cuarto, del cual utilizo un pasaje que contiene 1.700 palabras (pp. 13-19). 
(U. léxica $=$ Unidad léxica; $U$. fraseol. $=$ unidad fraseológica; DRAE = Diccionario Real Academia $;$ DA = Diccionario de Americanismos; $M M=$ María Moliner).

\begin{tabular}{|c|c|c|c|c|c|}
\hline $\begin{array}{l}\text { U. léxica } \\
\text { U. fraseol. }\end{array}$ & $\begin{array}{l}\text { DRAE } \\
1992 \\
\end{array}$ & $\begin{array}{l}\text { DRAE } \\
2001\end{array}$ & $\begin{array}{l}\text { DRAE } \\
2014 \\
\end{array}$ & DA. & $\begin{array}{c}\text { Definición / } \\
\text { particularidad }\end{array}$ \\
\hline al parejo & no & no & no & no & ¿en paralelo? \\
\hline armador & no & no & sí & sí & percha («jubón» en MM) \\
\hline bebezón & sí & & & sí & rec. como «bebedera» \\
\hline blandón & no & sí & sí & & candelero $(\mathrm{MM})$ \\
\hline cabellón & no & no & no & no & $\begin{array}{l}\text { denominación: de una } \\
\text { raza de indígenas }\end{array}$ \\
\hline cañuto & no & sí & sí & no & caña (sí en MM). \\
\hline chachaco & no & sí? & sí? & & chachajo? (2001) \\
\hline conversor & no & no & no & no & $\begin{array}{l}\text { religioso que trabaja en } \\
\text { una misión. }\end{array}$ \\
\hline cumbrera & no & sí & sí & no & pieza de madera \\
\hline chonta & & & & sí & palma \\
\hline estantillo & no & no & no & sí & en MM, estaca de madera \\
\hline fustán & no & sí & sí & sí & enagua \\
\hline garapacha & no & sí? & sí? & no & caparazón, cambio de g. \\
\hline majarama & no & no & no & no & $\begin{array}{l}\text { indigenismo para designar } \\
\text { una especie de cera }\end{array}$ \\
\hline masato & no & no & no & sí & bebida fermentada \\
\hline pacaco & no & no & no & no & especie de árbol \\
\hline palmiche & sí & sí & sí & sí & palmera amarga \\
\hline reboso & no & no & no & no & $\begin{array}{l}\text { MM: rebozo, modo de lle- } \\
\text { var la capa }\end{array}$ \\
\hline saltainas & no & no & no & no & saltana? \\
\hline sáparo & no & no & no & no & $\begin{array}{ll}? \\
\end{array}$ \\
\hline tocada & no & & sí & no & variante de tocata \\
\hline
\end{tabular}

9 Tomamos como base de registro el DRAE, obviamente, pues a pesar de que en ocasiones otros diccionarios le superan en riqueza, este es el normativo. Partimos de la edición de 1992,que comparamos con la de 2001 y la de 2014 con el objeto de constatar, por una parte el retraso de funcionamiento de nuestro diccionario, y segundo, la recuperación del tiempo perdido que en los últimos años se ha producido en la actividad de las academias. También como contraste consideramos el Diccionario de americanismos y oportunamente el María Moliner. 
En el pasaje seleccionado, de 1.700 palabras, de la cuales casi la mitad (entre el 30 y $40 \%$ ) son «palabras gramaticales» (= sin valor semántico: pronombres, conjunciones, preposiciones, etc.), se encuentran numerosos americanismos correspondientes a «reales» propios del entorno físico o social (achiote, barbudo, pilche, tocuyo ${ }^{10}$ ) recogidos ya en los diccionarios consultados, pero ocurren 16 unidades léxicas que no se hallan en alguna de las ediciones del DRAE (lo que supone aproximadamente el $2 \%$ de las palabras con significación semántica). 11 vocablos no están recogidos en el DA. El diccionario de colombianismos consultado tampoco proporciona mejor resultado: casi todas están ausentes en él. Las voces no recogidas son: cabellón, cañuto, conversor, chachaco, cumbrera, garapacha, pacaco, reboso, tocada, saltaina, sáparo. Hay un indigenismo explicado y dos incluidos sin explicación.

El siguiente texto escogido como prueba de lexicografía deficitaria nos sitúa en Costa Rica, es decir, en otro ámbito cultural con sus correspondientes diatopismos, y a un siglo de distancia del anterior. Se trata de las Concherías (2012) de Aquileo Echeverría, una colección de poemas que recoge poéticamente el mundo rural de la Costa Rica finisecular. Obviamos el abundante marcaje diastrático de muchas voces, ya que, procedente de una concepción realista del texto, intenta recuperar el habla popular. Cosa por lo demás natural en la estética de confesión realista.

El libro fue publicado en 1905 e introducido por Rubén Darío. Viene marcado por numerosos costarriqueñismos. Escogemos un poema al azar, «La vela de un angelito» (pp. 5-8), en el que poeta utiliza 580 palabras, de gran carga diastrática, teniendo en cuenta que el poeta costarriqueño utiliza el habla deturpada

10 Una de las unidades léxicas propuestas por Ricardo Palma para su inclusión en el DRAE. 
de los campesinos ticos. Narra el decurso de un banquete de funeral que acaba en un sarao evidente.

Concherías de Aquileo Echeverría (español costarriquense)

$(U$. léxica $=$ Unidad léxica $; U$. fraseol. $=$ unidad fraseológica; $D R A E$ = Diccionario Real Academia; DA = Diccionario de Americanismos; $M M=$ María Moliner; $C R=$ costarriqueñismo $)$.

\begin{tabular}{|c|c|c|c|c|l|}
\hline $\begin{array}{c}\text { U. léxica } \\
\text { U. fraseol. }\end{array}$ & $\begin{array}{c}\text { DRAE } \\
1992\end{array}$ & $\begin{array}{c}\text { DRAE } \\
2001\end{array}$ & $\begin{array}{c}\text { DRAE } \\
2014\end{array}$ & DA & Definición/particularidad \\
\hline atipar & & & sí & sí & atiforrarse, indicada como cr \\
\hline canchao & & & sí & sí & $\begin{array}{l}\text { ponerse una prenda de vestir } \\
\text { que no queda bien }\end{array}$ \\
\hline casusa & no & no & no & no & \\
\hline chonete & & & sí & sí & $\begin{array}{l}\text { sombrero de lona blanda, indi- } \\
\text { cada como cr }\end{array}$ \\
\hline cojoyito & no & no & no & & cojollito: persona distinguida \\
\hline cuecha & no & & sí & sí & $\begin{array}{l}\text { porción de tabaco que se mas- } \\
\text { ca }\end{array}$ \\
\hline limeta & no & no & no & sí & hacer limetas: no ser fácil \\
\hline nor & no & & sí & sí & abreviación de señor \\
\hline planazo & no & no & sí & sí & $\begin{array}{l}\text { golpe con la parte plana del } \\
\text { machete, indicada como cr }\end{array}$ \\
\hline rajonada & no & no & sí & sí & jactancioso, indicada como cr \\
\hline soca & no & no & sí & sí & borrachera \\
\hline tranquera & sí & no & sí & sí & portón rústico \\
\hline
\end{tabular}

En el texto escogido encontramos 15 unidades léxicas, sobre un total de 580 palabras, con marca «marcadamente» diatópica, algunas de ellas recogidas en los diccionarios (atipar [atiforrarse], ayote [calabaza], azafate) amén de muchas deturpaciones de carácter diastrático. 2 de esas unidades no están recogidas tampoco en el DA (casusa, cojoyito). No figura ningún indigenismo.

El tercer texto nos sitúa en Perú, en la época actual, en una región cuya habla supone ya una variación frente al español peruano general: la región de Cajamarca, en la provincia de 
Contumazá. Cuentos del tío Lino (1980), escritos en un español peruano, marcado dialectal e idiolectalmente, son una colección de relatos debidos a la pluma y pincel del artista cajamarquino Andrés Zevallos (1916/2017), que recoge la ingenuidad rural, así como el habla popular de la región, plagada de voces deturpadas y «rusticismos». Se le ha llamado el último pintor indigenista, quizás por haber sido alumno de Sabogal. Más que el mundo quechua, en su pintura y en su dicción está la ruralidad de la sierra andina.

Cuentos del tío Lino, de Andrés Zevallos (español dialectal de la sierra peruana)

(U. léxica $=$ Unidad léxica; $U$. fraseol. $=$ unidad fraseológica; $D R A E$ = Diccionario Real Academia; DA = Diccionario de Americanismos; $M M=$ María Moliner .

\begin{tabular}{|c|c|c|c|c|l|}
\hline $\begin{array}{c}\text { U. léxica/ } \\
\text { U. fraseol. }\end{array}$ & $\begin{array}{c}\text { DRAE } \\
1992\end{array}$ & $\begin{array}{c}\text { DRAE } \\
2001\end{array}$ & $\begin{array}{c}\text { DRAE } \\
2010\end{array}$ & DA & \multicolumn{1}{|c|}{$\begin{array}{c}\text { Definición/ } \\
\text { particularidad }\end{array}$} \\
\hline arrebiatar & no & sí & & sí & estar de acuerdo \\
\hline budo & no & no & & no & \\
\hline calatearse & no & sí & & sí & desnudarse \\
\hline das & no & no & no & no & interjección \\
\hline en campanillas & no & no & & no & desnudo \\
\hline enjalmo & no & no & & no & $\begin{array}{l}\text { enjalma (aparejo de } \\
\text { bestia de carga }\end{array}$ \\
\hline favorecerse & & & & no & $\begin{array}{l}\text { favorecerse de una } \\
\text { persona }\end{array}$ \\
\hline golgolear & no & no & no & no & onomatopeya? \\
\hline guardabajo & no & no & & no & \\
\hline guatopillas & no & no & no & no & \\
\hline huisa & no & no & & no & Interjección \\
\hline inverna & no & sí & sí & sí & terreno cercado \\
\hline jalca & no & sí & & sí & zona de la puna \\
\hline llamar el cuerpo & no & sí & & no & exonerar el cuerpo \\
\hline llushpe & no & no & no & no & Interjección \\
\hline parvada & sí & sí & sí & sí & conjunto de aves \\
\hline pauco & no & & & no & pauca: árbol \\
\hline peara & no & & & no & \\
\hline recordar & sí & sí & & & despertar \\
\hline sopino & no & sí & & sí & ano \\
\hline topetearse & no & sí & & sí & variante de topetar \\
\hline
\end{tabular}


Son numerosísimas voces marcadas por lo diastrático, idiolectal y dialectal, amén de americanismos, andinismos y arcaísmos los Cuentos del tío Lino: iajo! [eufemismo por carajo], bobo [= corazón $]$, cabuya $[=$ fibra $]$, calato $[=$ desnudo $]$, chancaca $[=$ azúcar de caña], gramalotar [= zona de gramalote], oración [arcaísmo por atardecer], jalar, paco $[=$ rojizo], parvada $[=$ conjunto de aves], pirca [= pared de piedra], ruco [= persona de dad], etc., de los cuales 18 vocablos no figuran en el DRAE de 92, cifra que se reduce a 8 en la edición de 2001; 11 no registrados en el DA. Hay 3 interjecciones dialectales (Llushpe, huisa y das) que no figuran en ningún diccionario. En el texto no aparecen indigenismos.

Con el cuarto texto nos situamos a un siglo de distancia y en Colombia: «En la diestra de Dios Padre» (1996, p. 13), uno de los Cuentos (1996) de Tomás Carrasquilla, autor colombiano de finales del XIX que en algunos aspectos podría valer como el Palma de ese país. El pasaje elegido contiene unas 1.500 palabras y glosa la bonhomía de un campesino antioqueño.

Cuentos de Tomás Carrasquilla

(U. léxica $=$ Unidad léxica; $U$. fraseol. $=$ unidad fraseológica; $D R A E$ = Diccionario Real Academia; DA = Diccionario de Americanismos; $M M=$ María Moliner .

\begin{tabular}{|c|c|c|c|c|l|}
\hline $\begin{array}{c}\text { U. léxica/ } \\
\text { U. fraseol. }\end{array}$ & $\begin{array}{c}\text { DRAE } \\
1992\end{array}$ & $\begin{array}{c}\text { DRAE } \\
2001\end{array}$ & $\begin{array}{c}\text { DRAE } \\
2010\end{array}$ & DA & Definición/particularidad \\
\hline afugias & no & no & no & sí & dificultad \\
\hline baharaque & no? & & & sí & $\begin{array}{l}\text { bajareque?, mezcla de barro } \\
\text { (no en MM) }\end{array}$ \\
\hline bungo & no & & no & no & $\begin{array}{l}\text { en MM: bunga: trampa } \\
\text { (cubanismo). En Ec., mosca }\end{array}$ \\
\hline cabecipelón & no & no & no & no & icontrario de cabecipeludo? \\
\hline cachumbo & sí & sí & sí & sí & rizo de pelo \\
\hline cantaleta & sí & sí & sí & sí & \\
\hline cargamanto & no & no & no & no & \\
\hline cariseca & no & no & no & sí & arepa \\
\hline comistraje & sí? & sí? & sí? & sí? & ¿variante de comistrajo? \\
\hline corotos & sí & sí & sí & sí & \\
\hline
\end{tabular}




\begin{tabular}{|c|c|c|c|c|c|}
\hline $\begin{array}{l}\text { U. léxica/ } \\
\text { U. fraseol. }\end{array}$ & $\begin{array}{l}\text { DRAE } \\
1992 \\
\end{array}$ & $\begin{array}{l}\text { DRAE } \\
2001\end{array}$ & $\begin{array}{l}\text { DRAE } \\
2010\end{array}$ & DA & Definición/particularidad \\
\hline cuyabra & no & no & no & sí & $\begin{array}{l}\text { registrado como natural de } \\
\text { armenia (col.) }\end{array}$ \\
\hline dentrar & no & no & no & Sí & variante de entrar \\
\hline desculcá & sí? & sí? & sí? & no & $\begin{array}{l}\text { ¿variante de esculcar? } \\
\text { espiar, registrar }\end{array}$ \\
\hline dizque & Sí & & & sí & adverbio \\
\hline empella & Sí & & & sí & manteca de cerdo \\
\hline entón & no & no & no & no & variante de «entonces» \\
\hline escusa & sí & Sí & sí & sí & tejido de carrizo \\
\hline garabato & sí & sí & sí & sí & vara colgada del techo \\
\hline gulumgiar & no & no & no & no & \\
\hline hilachento & no & no & no & sí & vestido de harapos \\
\hline jartar & no & no & & sí & tomar alcohol \\
\hline lámparo & no & no & no & no & \\
\hline limosnero & sí & sí & sí & sí & pordiosero \\
\hline llaguientos & no & no & no & no & sinónimo de llagoso \\
\hline ojitriste & no & no & no & no & \\
\hline pajarate & no & no & no & no & \\
\hline pobrecía & no & no & no & sí & \\
\hline ruco & sí & sí & sí & & viejo, inútil \\
\hline sargentiar & sí & sí & sí & no & variante de sargentear \\
\hline taita & sí & sí & sí & sí & padre \\
\hline tutumadas & no & sí & sí & sí & $\begin{array}{l}\text { lo que cabe en una tutuma. } \\
\text { (sí en MM) }\end{array}$ \\
\hline veleña & no & no & no & no & \\
\hline
\end{tabular}

En el pasaje de este cuento de Carrasquilla (1996, pp. 1326) hemos identificado 27 palabras con marcas diatópicas o diacrónicas (cachumbo [rizo], coroto, dizque, taita, ruco, limosnero [en el sentido de pordiosero], garabato [vara colgada del techo], escusa [tejido], sangentear, etc.), 17 sin registro en el DRAE. Aunque el sentido que construye intuitivamente el lector por encima de los «blancos» de comprensión que produce el léxico desconocido, no se ve sustancialmente perjudicado, la lectura comprensiva queda incompleta y pone en evidencia lo por hacer lexicográficamente.

\section{Valoración y conclusión}

«No se trata de indigenizar el español», decía Arguedas en su introducción a Yawar fiesta (1977) pero sí, permítase el añadido, 
de mestizarlo... aunque solo sea por el simple hecho de que hoy en día, como casi todas las lenguas, el español es mestizo. Y mejor mestizarlo con la sangre literaria más próxima... y al mismo tiempo más diferente. Si hemos admitido «burofax», «morse», «grafiti» o «chucrut», ¿por qué no enriquecer nuestro idioma con términos tan específicos como «collavino» (habitante del Collao), k'eñwa («árbol chato de corteza roja», define Arguedas), el apu protector, el insecto volador llamado tankayllu, el volar planeando de los cóndores o awankay, o la caña selvática mámak que son o culturemas o visiones propias andinas? Sobre todo una vez que se hallan recogidos por Arguedas en Los ríos profundos. Palma fue contrario a los quechuismos en el diccionario, pero los tiempos han cambiado. ¿Y por qué si el DRAE recogía «pacense» para expresar al natural de Badajoz o «huancaíno» para el natural de Huancayo, no recoge, por ejemplo, «collavino»? ¿Alguna vez veremos el comilfó cortazariano en nuestro diccionario?

Ahora bien, ese mestizaje no debe ser unidireccional, introvertido, sino doble y múltiple. Hoy se habla de «lengua general» frente a «variante americana» $y$ ordinariamente se entiende esta lexicografía inclusiva en el sentido de que el «español general», tradicionalmente conceptuado como peninsular, debiera incorporar las aportaciones hispanas, pero no a la inversa y a la mutua. Además, la variación americana no es unitaria. Los esfuerzos de comprensión deben ser mutuos. Yo no sé si «no perder comba», o «caerse del guindo» son unidades fraseológicas que se comprendan en todas las latitudes del español. Hay que americanizar el español general, pero también hay que españolizar el habla americana en aras del común entendimiento. Y argentinizar la norma peruana y a la inversa. O peruanizar el habla chilena. Dicho de otra manera, lo mismo que el «español general», al que ordinariamente se concibe como castellano, debe abrirse a la diatopía argentina o a la peruana, 
también el habla peruana debe abrirse, no solo a la peninsular, sino también a la diatopía mejicana o a la dominicana.

Así pues, se trataría de 1) seguir en la senda abierta por Ricardo Palma en lo referente a lo que podíamos llamar el inclusivismo lexicográfico incorporando al español general el mayor número de lemas, dejando aparte, por supuesto, deturpaciones evidentes ${ }^{11}$; 2) de generar una conciencia comunicativa que intente enriquecer la propia expresión con las variantes que el prójimo, nunca mejor dicho, nos aporta en su visión del mundo desde la propia situación.

Se trata no solo de hacer realidad lo que Arguedas decía del español cuyo hablante en estas tierras «se ve en la necesidad de tomarlo como un elemento primario al que debe modificar, quitar y poner, hasta convertirlo en un instrumento propio», sino también del proceso inverso: de localizar lo universal (las diversas diatopías hispanas) para hacer más universal lo local. Y en eso la lectura de la literatura es un instrumento imprescindible. Leamos a Palma o a Vallejo en España, Méjico y en Argentina y, a la inversa, a Borges, a Unamuno, a ValleInclán o García Márquez en Perú.

Así se potenciaría lo que el mismo Arguedas llamaba «la ilimitada virtud del castellano». Personalmente como usuario profesional del diccionario (en cuanto traductor y crítico de la traducción y de la literatura) no estoy de acuerdo con las normas de restricción del Diccionario esencial de la lengua española (Madrid, 2006) que se aplica, por ejemplo, al léxico dialectal (las marcas de país 5 y 3 ). La falta de consideración de cualquier área lingüística (de las 12 que señala) hará difícil la lectura

$11 \mathrm{Al}$ respecto cabe indicar que más de una están todavía presentes en el uso real lingüístico en el subcontinente. Tal, por ejemplo, la neutralización de la «z», fonema que no solo va perdiendo el sonido, sino incluso la grafía. No es infrecuente ver escrito, por ejemplo, «losa» en vez de «loza». 
de los textos que, de cuño más o menos realista o popular, recojan coloquialismos, vulgarismos, etc. y más difícil aun la tarea de traducción. ¿Por qué se recoge solo el léxico común y culto actual del repertorio? ¿Por qué desparecen lemas que dejaron de usarse durante las primeras décadas del siglo XX? Con semejante «diccionario esencial» no podríamos consultar un lema de las obras de Valera o de Ricardo Palma. Son muchos los diccionarios del español (Panhispánico de dudas, Esencial, Diacrónico, histórico, Manuel Seco, María Moliner [2012], etc.), pero sería de desear un diccionario de referencia absoluta al estilo del Grimm alemán o del Oxford inglés. 


\section{APÉNDICE}

\section{Textos utilizados}

Presentamos como apéndice una selección de pasajes de los textos que hemos vaciado en busca de variantes y americanismos. En aras de la extensión limitada los presentamos en versión abreviada a título de ejemplo.

\section{I.- Juan de santa Gertrudis, OFM, Las maravillas de la naturaleza}

Ya que me vi solo con mi chapetón don Francisco, díjeles a los indios: De aquí a pocos días me traerán de Caquetá otra porción de ganado, el cual os repartiré a vosotros, para que cada familia tenga su ganado, el cual poco a poco irá multiplicando, y con ello, con el tiempo de aquí a pocos años, todos tendréis buena carne qué comer. Por lo cual es menester que se prevenga lo más pronto de pasto, para que no perezca. Y así me parece que todos os apliquéis al trabajo y que se abra una buena roza, capaz para que todos tengan qué comer. Ellos respondieron que sí, y que todos trabajarían lo que yo mandase. Con esta determinación me fui con el capitán y cuatro indios más río abajo, y a cosa de una milla había una buena loma, la que registramos, y me pareció muy a propósito para ello, porque aunque monte adentro, no era toda llana, pero formaba una quebradita, y con ella tendría allí el ganado agua para beber sin haber de bajar a beber al río. Ya íbamos prevenidos de machetes, y con ello aquel mismo día abrieron una trocha hasta el pueblo. Yo me vine siguiendo los pasos por el río con la canoa hasta que llegamos al pueblo; y a la noche, después de rezar les dije que por aquel caminito nos habíamos de ir cada día a abrir la roza, y todos los cedros, chachacos y guayacanes que se topasen, que los dejasen en pie, y que éstos se cortarían después de haber quemado la roza, porque yo los quería para estantillos para fabricar una buena iglesia. ... alláronse tres cedros, siete chachacos y cinco guayacanes. Todos se cortaron, y haciendo de los tres cedros como una balsa, entreverándoles guaduas, sobre de ello se cargaron los guayacanes y los chachacos, y por el río se acarreó todo al pueblo. Viendo yo 
que el un cedro era de forma mayor, mandé cortarle veinticinco varas de lo más grueso y lo destiné para hacer de ello una buena canoa. Esta se fabricó después de medio año, y me salió una canoa que tenía siete cuartas de ancho, capaz de bogarse con cuarenta indios con su canalete, y de llevar sobre cincuenta quintales. Ya que me desocupé de la roza, puse mano en cortar camisas, fustanes, faldillas, rebosos, calzones, armadores y chupas para todos los hombres y mujeres, ordenando al mismo tiempo que todas las mujeres cada semana me habían de traer un ovillo de hilo de algodón, y que lo habían de hilar con las manos limpias; porque como todas se pintaban de achiote no me saliese el hilo colorado. Ello todas lo prometieron hacer así, pero apenas hubo una que no lo trajese lleno de achiote [...] Algunas por fin algo las industrié, y llegaron a no coser mal; pero su cosido por más cuidado que yo aplicaba, me salía todo tiznado de achiote. Yo puedo asegurar que por espacio de cuatro meses casi no hice otra cosa más que coser, hasta que se acabó todo. Sólo quedaron los niños y las niñas sin vestido. Ya que lo tuve todo alistado, teñí los fustanes del color morado con la hoja del árbol pacaco, para que así no se les conociese tanto el mugre. El día de Jueves Santo les repartí el vestido a cada cual, para que así todos vestidos asistieran a la misa que celebré con mucho gusto mío espiritual. ...Y siempre que dijera yo misa, me había de asistir con la escopeta en la mano del lado del altar; porque muchas de las muertes que han hecho los indios de varios Padres conversores, los habían acometido cuando decían misa. Para pues esta primera misa que celebré este Jueves Santo, empezó el chapetón el oficio de estar guardándome, puesto de centinela al lado del altar, y con esta seguridad decía las misas sin sobresalto.... Ya que se pasaron las fiestas de pascua, habiendo ya llegado el resto del ganado, empezando ya a haber bastante pasto en la nueva rocería, se traspasó a ella todo el ganado, así vacuno como ovejuno, y entonces apliqué la gente a agrandar la roza antigua al parejo de la nueva, y con ello conseguí pasto bastante para todo, porque cuando se acababa el pasto de la una roza, ya en la otra había procreado bastante, y así cada cuatro meses se mudaba todo el ganado de una roza a otra, y nunca faltaba, antes siempre se multiplicó. ... Ya hecho el repartimiento, les dije: que 
yo había de mandar a Quito un poco de cera blanca que ellos llaman maja rama... y así les dije que en topando de ella me la trujeran.

\section{Aquileo Echevarria, Concherías, «La vela del angelito»}

Apenas el rezador// pone fin á lo que reza,// cuando sale á relucir// la hidrópica botijuela.// iQué besos tan cariñosos!//iQué caricias tan extremas!// Unos la apuntan al muro,// los más hacia las soleras.// Libre la sala de estorbos,// puesta en un rincón la mesa,// donde en caja destapada// duerme el Ángel que se vela,// adelanta el maestro Goyo,// que es el director de orquesta,// con el chonete canchao,// bajo el brazo la vihuela,// en la boca el cabo hediondo// que ha llevado tras la oreja,// cabo que ha de ser al cabo// soberanísima cuecha.// Da principio el zapateado.// Cómo saltan y dan vueltas,// se detienen ó adelantan,// se separan ó se estrechan.// Ellas con la falda asida// y la mano en la cadera.// Ellos con pañuelo al cuello// ó en la mano, según quieran.// Ahora dando pataditas,// ya girando con presteza,// van de la una á la otra banda,// van de la una á la otra puerta.// Envuélvelos una nube //que forma la polvareda// que por los pies arrancada// surge del piso de tierra;// nube contra la que luchan// en vano doce candelas// colocadas en pantallas// que de las paredes cuelgan,// ó adheridas al horcón// de recia y tosca madera,// donde dejan al morir// sebo, hollín, pabilo y yesca.// Alguien grita: ibomba! ibomba!// Párase al punto la orquesta// y un mozo de buena estampa// así dice á su mozuela:// «Como mi almuada es de paja// y mi novia no está vieja,// toda la noche la paso// con la paja tras la oreja»//. • iBravo! iBien! iBiba Domingo! // iBiban ñor José y Grabiela!// iBiban los dueños de casa! //iOtro trago pa l'orquesto!//iMúsica mestro, y arréle// que ya encontré compañera!// —iOh biejiyo tan asiao//iQue biba yo y mi pareja!//iQue biba! iBomba! iOtra bomba!// Párase al punto la orquesta,// y la niña puesta en jarras,// responde así zalamera:// «Quisiera ser cojoyito //ó flor de la yerbabuena,// para perfumarle el alma// al negro que me quisiera.»// Bueno! iMuy bueno, caramba!// —Alcánsensen la limeta,// que la casusa hace falta// y es casusa de cabeza.// Dame un trago, Valentín //Sampále, que no hay tranquera.// Los mozos de la familia// 
á las jóvenes obsequian,// repartiendo en azafates sendas copas de mistela,// que toman en compañía// de empanadas de conserva,// polvorones, pan de rosa// ó enlustrados con canela;// mientras las damas mayores,// con la escudilla en las piernas,// se atipan de miel de ayote,// usando para comerla// de sus no pulidos dedos// las sus no muy limpias yemas.// Fortalecidas las panzas// sigue de nuevo la juerga,// y entre risas y palmadas// se inician juegos de prendas;// «San Miguel dame tus almas»;// luego «La gallina ciega»,// luego «El estira y encoge»,// «El muerto»y «La mula tuerta».// En tanto allá en la cocina// la madre suda y se empeña,// ya batiendo chocolates,// ya saqueando su alacena// donde el bizcocho dorado/ duerme en amplias cazuelejas,// ó ya sacando empanadas// de papa y carne rellenas,// ruborizadas de achiote y trasudando manteca. El padre con una "soca"// de más allá de la cuenta,// suelta un rosario de verbos// y "rajonadas" tremendas,// diciendo que allí no hay// hombres que se "paren”;// que son hembras,// y que el que quiera probarlo// que se salga á la tranquera,// pa arriarle cuatro planazos// y hacerle ver las estrellas.... La gentil aurora pone fin,// con su luz, á la fiesta:// y al niño, en la caja blanca,// se llevan para la aldea,// donde le aguarda// el regazo cariñoso de la tierra.

\section{Andrés Zevallos, Cuentos del tío Lino (selección)}

«La chancaca pa la chicha»

Un año el Tío Lino se apuntó de Mayordomo de la Fiesta del Patrón San Mateo. Estaba cerca el veintiuno y la Tía Chuspe le pidió chancaca pa la chicha: ¿Y hoy quíago?, dijo el Tío, dándose cuenta que ya no había tiempo pa ir hasta el Membrillar a compralo. Eneso vio una avispa encima de una flor y idas! lo pescó, le amarró la punta de un ovillo de hilo fino y lo soltó...

La avispa vuelva y vuelva, derecho al cerro Cunanten, y el Tío suelta y suelta hilo hasta que paró; entónse fue ovillando el hilo hasta que llegó a un panal llenecito de miel questaba colgao diuna peña dese cerro, lo jaló y lo llevó paque la Tía endulce la chicha, que salió buenaza. 
«Desde cuándo hay conejos»

Fue que la Tía Chuspe crió tanto cuy que ya no había sitio ni qué dales de comer. Entón con el Tío pensaron llevalos a Contumazá pa vendelos. Como eran hartos, el Tío se puso a inventar cómo luiba hacer pa no tener mucho trabajo. Se puso a pensar y diun rato le dijo a la Chuspe: le echo lazo al ruco padre, monto en mi macho y lo voy jalando al ruco, mientras tú los vas sacando del cuyero paque lo sigan; cuando acabes, te vienes arreándolos, no sea que se queden puel camino.

Ya estaban entrando al pueblo por el Kike y los últimos cuyes tuavía estaban asomando por Las Alverjas. Eneso salió un perrazo bravo que los acabó de espantar; unos se metieron por las pircas y otros se fueron por los cerros, orejeando porónde venía el perro; ahí fue que les crecieron las orejas y desde entón hay conejos en el campo.

\section{«Como el tío Lino conoció Trujillo»}

El Tío Lino había pasao todita la mañana andando de sol a sol por el potrero cuando llegó a una quebrada empapadito de sudor. Al ver el agua fresquita no aguantó las ganas, luego luego se calateó y se metió en un pozo quiabía debajo de unos alisos. Estaba en todo el baño, cuando oyó un rumor fuerte por el aire, miró y vió un condorazo paco que daba vuelta bajito mirando su ropa... Caray, dijo, ¿qué quiere este?, estará creyendo que me he muerto, ihoy va ver! Calladito se preparó y cuando pasaba el cóndor das lecho lazo del pescuezo. El buitre se asustó y alzó vuelo. El Tío quizo sujetalo pero el cóndor lo levantó así, calato como estaba. ¿Y hoy quiago?, dijo, mientras subía y subía, volando sobre potreros y casas. Nuaymás que agarrarse fuerte, pensó. Pero eneso se asustó y empezó a gritar: iTiendan colchooones... tiendan colchooones! La gente salía a ver qué pasaba y mirando arriba decían: Es el Arcángel San Gabriel en campanillas, y se arrodillaba sin hacer caso del pedido. Vuela y vuela ya le fue gustando y entón le vino la idea: subió por el lazo hasta cerca del cóndor y le rogó que lo lleve a conocer Trujillo, aunque sea desde arriba, porque él había llegao hasta 
Ascope nomá. El cóndor le hizo el gusto y, tarde ya, lo dejó tiritando en el mismo sitio del baño, mientras el Tío le sacaba el lazo.

\section{Carrasquilla, Cuentos}

«En la diestra de Dios Padre».

Este dizque era un hombre que se llamaba Peralta. Vivía en un pajarate muy grande y muy viejo, en el propio camino real y afuerita de un pueblo donde vivía el Rey. No era casao y vivía con una hermana soltera, algo viejona y muy aburrida.

No había en el pueblo quién no conociera a Peralta por sus muchas caridades: él lavaba los llaguientos; él asistía a los enfermos; él enterraba a los muertos; se quitaba el pan de la boca y los trapitos del cuerpo para dárselos a los pobres; y por eso era que estaba en la pura inopia; y a la hermana se la llevaba el diablo con todos los limosneros y leprosos que Peralta mantenía en la casa. "¿Qué te ganás, hombre de Dios - le decía la hermana-, con trabajar como un macho, si todo lo que conseguís lo botás jartando y vistiendo a tanto perezoso y holgazán? Casáte, hombre; casáte pa que tengás hijos a quién mantener". "Cálle la boca, hermanita, y no diga disparates. Yo no necesito de hijos, ni de mujer ni de nadie, porque tengo mi prójimo a quién servir. Mi familia son los prójimos”. “iTus prójimos! iSerá por tanto que te lo agradecen; será por tanto que ti han dao! iAi te veo siempre más hilachento y más infeliz que los limosneros que socorrés! Bien podías comprarte una muda y comprármela a yo, que harto la necesitamos; o tan siquiera traer comida alguna vez pa que llenáramos, ya que pasamos tantos hambres. Pero vos no te afanás por lo tuyo: tenés sangre de gusano".

Esta era siempre la cantaleta de la hermana; pero como si predicara en desierto frío. Peralta seguía más pior; siempre hilachento y zarrapastroso, y el bolsico lámparo lámparo; con el fogoncito encendido tal cual vez, la despensa en las puras tablas y una pobrecía, señor, 
regada por aquella casa desde el chiquero hasta el corredor de afuera. Figúrese que no eran tan solamente los Peraltas, sino todos los lisiaos y leprosos, que se habían apoderao de los cuartos y de los corredores de la casa "convidaos por el sangre de gusano", como decía la hermana.

Una ocasioncita estaba Peralta muy fatigao de las afugias del día, cuando, a tiempo de largarse un aguacero, arriman dos pelegrinos a los portales de la casa y piden posada: "Con todo corazón se las doy, buenos señores - les dijo Peralta muy atencioso—; pero lo van a pasar muy mal, porqu'en esta casa no hay ni un grano de sal ni una tabla de cacao con qué hacerles una comidita. Pero prosigan pa dentro, que la buena voluntá es lo que vale". 


\section{Referencias bibliográficas}

Alvar López, Manuel. (1996). Manual de dialectología hispánica: el español de América. Barcelona: Ariel.

Arguedas, J. M. (1977). Yawar Fiesta. Buenos Aires: Editorial Pescadito. Arguedas, J. M. (2001). Los ríos profundos. Lima: PEISA.

ASALE/Real Academia Española. (2006). Diccionario esencial de la lengua española. Madrid: Espasa.

ASALE/ Real Academia Española. (2014). Diccionario de la lengua española.

ASALE (2015). Diccionario de americanismos Madrid: Taurus.

Carrasquilla, T. (1996). Cuentos. Bogotá: Imprenta Nacional de Colombia. Recuperado de https://davalor8Ig.files.wordpress. com/2012/08/carrasquilla-tomc3al s-cuentos.pdf

Diccionario Esencial de la Lengua Española. (2006). Prefacio. Madrid: Espasa.

Diccionario Pons [en línea]. (2017). Managing Director: Gabriele Schmidt, Publisher: Dr. h. c. Michael Klett. Stoeckachstrasse: Alemania. Recuperado de https://es.pons.com/traducci\%C3\%B3n Echeverría, A. J. (2012). Concherías. San José: Imprenta Nacional. Gutiérrez, J. M. (2004). Historia y Crítica. Selección y prólogo de Clara Rey de Guido. Caracas: Biblioteca Ayacucho.

Lorenzo, E. (1971). El español de hoy, lengua en ebullición. Madrid: Editorial Gredos.

Luis Fallas, C. (2012). Marcos Ramírez. 3era Edición. San José: Editorial Costa Rica.

Moliner, M. (2012). Diccionario de uso del español. Gredos: Madrid.

Oxford University Press (1991). Oxford English Dictionary. Preface. Oxford: Claredom 1991. 
Palma, R. (1893). Tradiciones Peruanas. Barcelona: Montaner y Simón. Recuperado de http://cdigital.dgb.uanl.mx/ la/1020132091/1020132091.html

Palma, R. (1903). Papeletas lexicográficas. Edición digital basada en la edición de Lima: Imprenta La Industria. Recuperado de http:// www.cervantesvirtual.com/obra-visor/papeletas-lexicograficas--0/ html/0 lc25 134-82b2-1 ldf-acc7-002185ce6064_2.html

Palma, R. (2003). Papeletas lexicográficas. Lima: Universidad de Martín de Porres.

Real Académia de la Lengua Española. Recuperado de https://www. rae.es/diccionario-de-la-lengua-espanola/presentacion

RAE, CORPES XXI. Español del siglo XXI. Recuperado de https://www. rae.es/recursos/ banco-de-datos/corpes-XXI

Rey, A. (2001). «Avant-propos». En Le Grand Robert de la langue française, XI. Lingüista.

Santa Gertrudis, Fr. J. de (1970). Las Maravillas de la naturaleza. Tomo I, II, III, IV. Prólogo de Luis Duque Gómez. Introducción de Jesús García Pastor (1956). Bogotá: Ed. Kelly, Biblioteca Banco Popular.

Zevallos, A. (1980). Cuentos del tío Lino. Lima: Ediciones Lluvia, Grupo de Trabajo Río. 